\title{
Current trends in orthognathic surgery
}

\author{
Hyung Joon Seo ${ }^{1}$, \\ Youn-Kyung $\mathrm{Choi}^{2}$ \\ Departments of ${ }^{1}$ Plastic and \\ Reconstructive Surgery and \\ ${ }^{2}$ Orthodontics, Biomedical Research \\ Institute, Pusan National University \\ Hospital, Busan, Korea
}

Orthognathic surgery has steadily evolved, gradually expanding its scope of application beyond its original purpose of simply correcting malocclusion and the facial profile. For instance, it is now used to treat obstructive sleep apnea and to achieve purely cosmetic outcomes. Recent developments in three-dimensional digital technology are being utilized throughout the entire process of orthognathic surgery, from establishing a surgical plan to printing the surgical splint. These processes have made it possible to perform more sophisticated surgery. The goal of this review article is to introduce current trends in the field of orthognathic surgery and controversies that are under active discussion. The role of a plastic surgeon is not limited to performing orthognathic surgery itself, but also encompasses deep involvement throughout the entire process, including the set-up of surgical occlusion and overall surgical planning. The authors summarize various aspects in the field of orthognathic surgery with the hope of providing helpful information both for plastic surgeons and orthodontists who are interested in orthognathic surgery.

Abbreviations: $A H I$, apnea-hypopnea index; $\mathrm{Al}$, artificial intelligence; $\mathrm{AR}$, augmented reality; BSSO, bilateral sagittal split osteotomy; MMA, maxillomandibular advancement; nCPAP, nasal continuous positive airway pressure; OSA, obstructive sleep apnea; 3D, three-dimensional; 2D, two-dimensional

Keywords: Cleft surgery / Facial asymmetry / Jaw surgery / Malocclusion / Obstructive sleep apnea / Orthognathic surgery

\section{INTRODUCTION}

Orthognathic surgery is commonly performed in the field of craniofacial surgery to address malocclusion, problems related to the facial profile, and obstructive sleep apnea (OSA) [1]. The goal of orthognathic surgery is to reposition the maxilla, mandible, and chin, and commonly performed procedures include LeFort I osteotomy and bilateral sagittal split osteotomy (BSSO) with or without osseous genioplasty [2-4].

The first mandibular osteotomy for the surgical correction of prognathism and class III malocclusion was performed by the

\footnotetext{
Correspondence: Hyung Joon Seo

Department of Plastic and Reconstructive Surgery and Biomedical Research Institute, Pusan National University Hospital, 179 Gudeok-ro, Seo-gu, Busan 49241, Korea

E-mail: payton100@hanmail.net
}

Received December 16, 2021 / Revised December 16, 2021 / Accepted December 20, 202
American surgeon Simon P. Hullien in 1849 [5,6]. The skeletal prognathism was corrected postoperatively, whereas there was an obvious limitation in the treatment of malocclusion after the surgery, which resulted in edge-to-edge malocclusion anteriorly. Since the 1970s, orthodontic treatment has become popular for the treatment of malocclusion, and it has been common to combine orthodontic treatment with orthognathic surgery to treat both the skeletal profile and malocclusion.

Both dental function and aesthetic goals should be achieved simultaneously through orthognathic surgery, and doing so requires consideration of both skeletal movement and soft tissue changes. In recent decades, the surgical goals of orthognathic surgery have shifted to become primarily aesthetic $[7,8]$. Although the functional goal of achieving ideal dental occlusion remains important, no one would be willing to accept negatively impacting the aesthetic results in order to achieve that goal. 
In the process of planning and performing surgery, the surgical goals are to achieve (1) a visually well-proportioned face, (2) skeletally well supported soft tissue, and (3) a pleasing facial countenance [3]. Recent trends in orthognathic surgery have evolved to minimize the period of preoperative orthodontic treatment and to combine three-dimensional (3D) technology in the process of surgical planning to improve accuracy.

\section{COMBINATION WITH ORTHODONTIC TREATMENT}

\section{Conventional approach}

The conventional approach is referred to as the orthodonticfirst approach. Preoperative orthodontic treatment is performed prior to orthognathic surgery to reveal the true skeletal discrepancy preoperatively and to reposition the maxilla and mandible, with the goal of achieving solid surgical occlusion to overcome postoperative occlusal instability [9]. Despite these advantages, preoperative orthodontic treatment has several critical disadvantages that cause substantial inconvenience for patients. During the preoperative period, dental decompensation causes a progressive deterioration of the facial aesthetic profile and dental function (Fig. 1). The most critical drawback of preoperative orthodontic treatment is its time-consuming nature, as it takes on average 12 to 24 months, and can even extend up to 48 months depending on the complexity of the patient's initial dental status $[10,11]$.

\section{Surgery-first approach}

The definition of the surgery-first approach is orthognathic surgery followed by postoperative orthodontic treatment without preoperative orthodontic treatment [12,13]. If the period of preoperative orthodontic treatment is minimized to less than 6 months, it is defined as the modified-surgery approach [14,15]. Although there are disagreements about the chronology, the first report of the surgery-first approach in Asia is thought to have been published in the Korean Journal of Clinical Orthodontics in 2002 [13,16]. The fundamental concept of the current surgery-first approach is well described in this publication.

The advantages of the surgery-first approach described in previous papers are shortening the total treatment time, a favorable direction of postoperative orthodontics (identical to the direction of natural compensation), early improvement of facial aesthetics, and early correction of OSA [9,17-19]. The surgeryfirst approach is usually indicated for patients who do not need much preoperative treatment, including those with (1) wellaligned to mildly crowded anterior teeth, (2) a flat to mild curve of Spee, (3) normal to mildly proclined or retroclined incisors, and (4) a minimal transverse discrepancy [13,17]. In recent years, the range of indications has been further expanded; according to Choi and Lee [13], if stable surgical occlusion is achieved through a simulation of postoperative orthodontic movement, the surgery-first approach could theoretically be applied to all patients who need orthognathic surgery. The orthodontist's experience and expertise are important, as well as the plastic surgeon's experience, for application of the surgeryfirst approach [20].

Yang et al. conducted a systematic review and meta-analysis to evaluate the evidence for the stability, efficacy, and outcomes of the surgery-first approach and the conventional approach. They concluded that the surgery-first approach group showed similar postoperative stability, reliability, and complication rates, with a shorter total treatment time [21-23].

\section{Orthognathic surgery without orthodontic treatment}

According to recent reports, most patients who are willing to
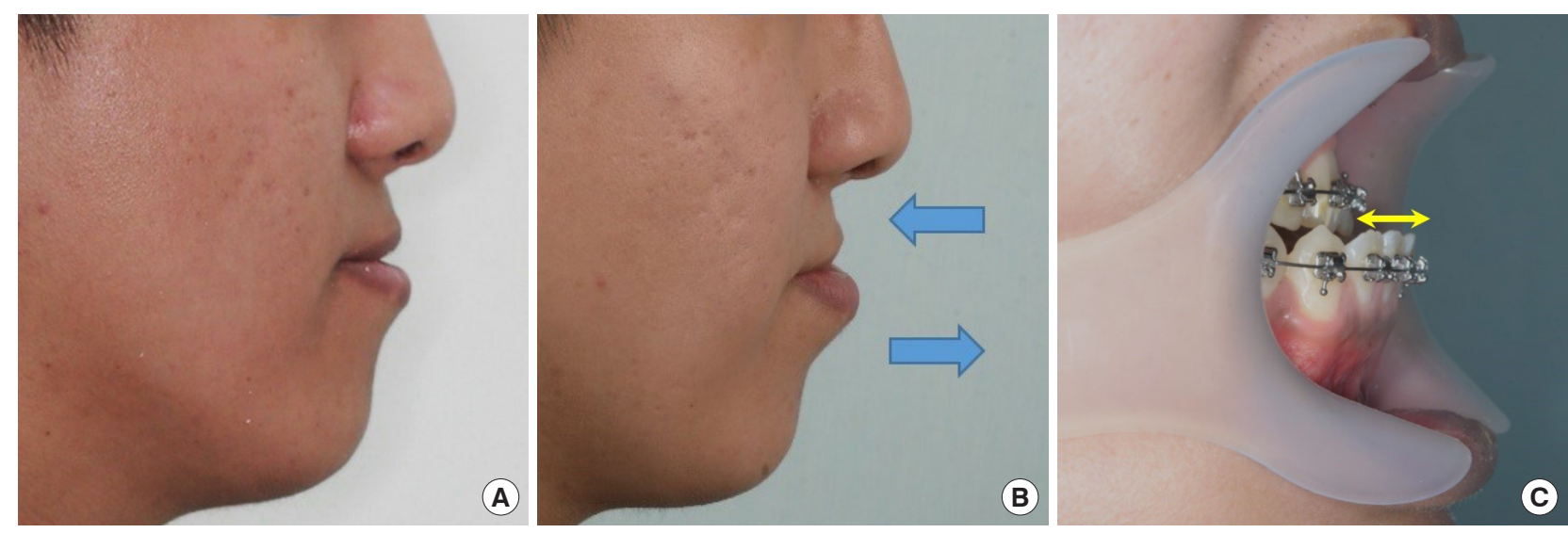

Fig. 1. A case of two-jaw orthognathic surgery with conventional approach. (A) Before preoperative orthodontic treatment. (B, C) During the treatment, dental decompensation caused a progressive deterioration of the facial profile (blue arrows) and dental function (yellow arrow). 
undergo orthognathic surgery visit clinics for cosmetic purposes rather than for functional reasons, such as occlusal problems or temporomandibular dysfunction $[24,25]$. Asians have a relatively flat facial profile, which is closely related to a low occlusal plane angle [26]. A high occlusal plane facial profile is preferred due to its aesthetically pleasing appearance. In order to improve the facial profile in patients with functionally normal occlusion but a low occlusal plane angle, orthognathic surgery could be performed with clockwise rotation of the maxillomandibular complex while maintaining the existing normal occlusion status. It is important for patients with normal occlusion who undergo orthognathic surgery to maintain their preoperative occlusal status after surgery in order to avoid orthodontic treatment. Lee and Park [24] reported that orthognathic surgery without orthodontic treatment was performed in 43 patients with normal occlusion but a low occlusal plane angle, and cosmetically satisfactory results with long-term stability were obtained (Figs. 2, 3).
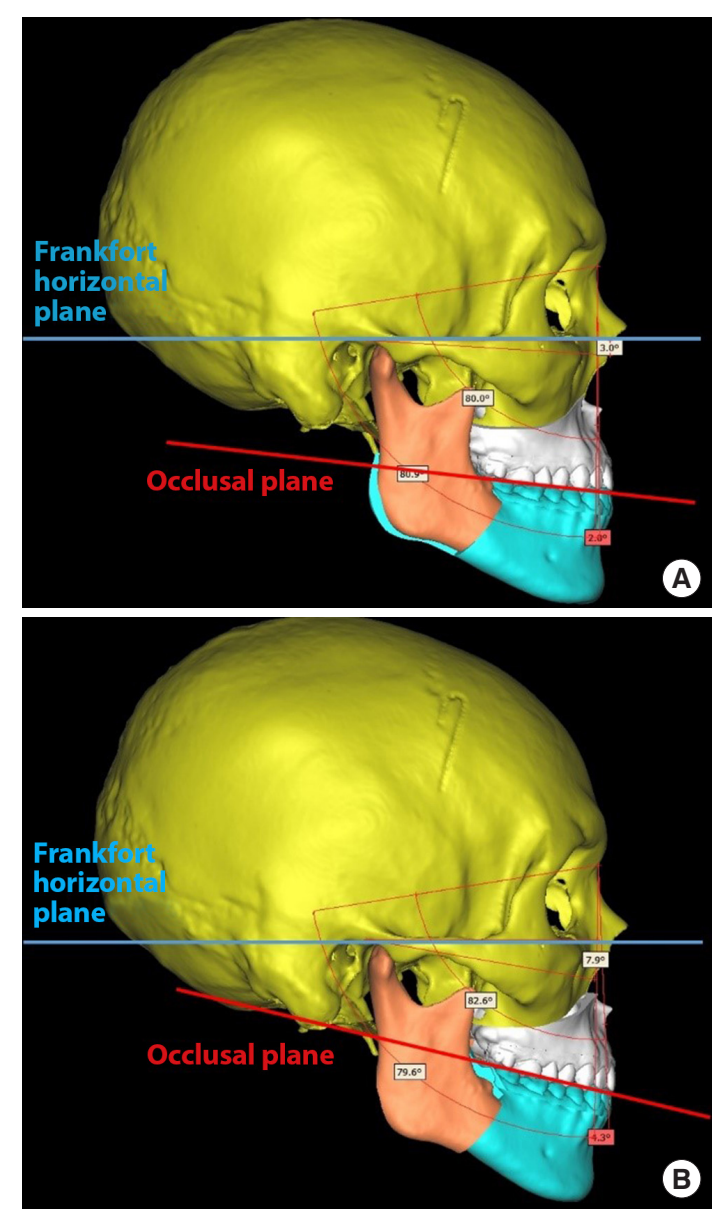

Fig. 2. Computer simulation of orthognathic surgery. (A) Asians have a relatively flat facial profile, which is closely related to a low occlusal plane angle. (B) After simulation, a high occlusal plane is achieved.

\section{SURGICAL PLANNING}

\section{Virtual surgical planning}

Model surgery was previously performed with a radiocephalometric analysis of the facial profile and malocclusion before surgery, and the intermediate and final splints were created according to the change in the maxillomandibular position. Recent advances in technology, including computer-assisted design with high-quality cone-beam computed tomography, have enabled precise surgical planning using a 3D virtual environment, which has created a paradigm shift in orthognathic surgery [27-30]. Virtual surgical planning has facilitated accurate diagnoses and detailed treatment planning through better visualization of 3D phenotypic changes. These advantages have improved the accuracy of osteotomy, enabled the fabrication of intermediate and final splints, and significantly shortened preoperative surgical planning with intraoperative osteotomies and fixation [31,32]. Wilson et al. [28] reported that there was a

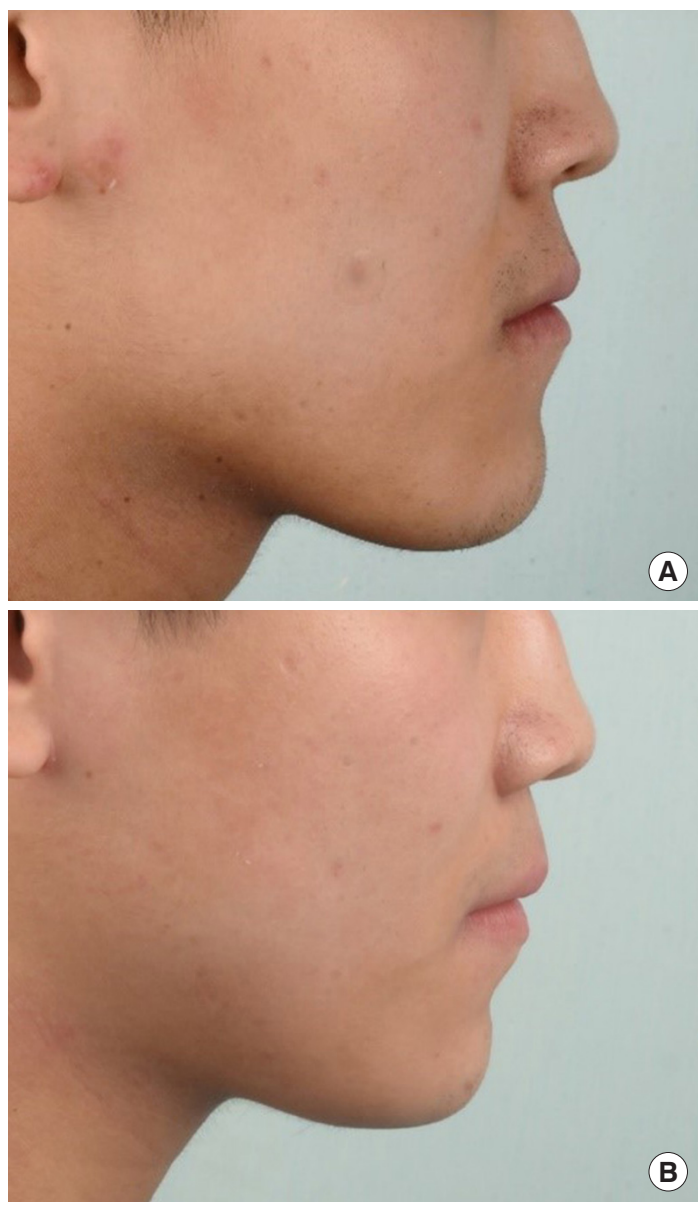

Fig. 3. The change of the occlusal plane angle has a great influence on the facial profile. (A) Preoperative and (B) postoperative photographs of a man with two-jaw orthognathic surgery without any orthodontic treatment. 
high degree of conformity when comparing the virtual surgical planning to the actual postoperative outcomes, except for some incongruent results of maxillary vertical and mandibular sagittal movement. Furthermore, 3D virtual planning also has advantages for soft tissue simulation with facial contouring, and Hsu et al. [33] reported that 3D planning presents superior facial contour symmetry outcomes than two-dimensional (2D) planning in unilateral cleft patients.

The use of a fabricated osteotomy cutting guide and prebended fixation plates based on virtual surgical planning increases the feasibility of planned osteotomies and repositioning of the maxillomandibular segment, thereby saving time [34].

\section{Virtual surgical occlusion set-up}

The surgical occlusion set-up is a vital step in planning for orthognathic surgery and is especially critical for adopting the surgery-first approach. Model surgery-based 2D lateral cephalometric analysis and usage of a dental model, known as the conventional method, was widely used. However, several disadvantages of the conventional method have been reported, including (1) patient discomfort during the dental impression procedure, (2) the time-consuming nature of model surgery, (3) the inconvenience of storing dental casts, and (4) the risk of accidentally breaking dental casts $[14,35,36]$.

Ho et al. [14] reported fully digital 3D planning using intraoral scanning and a 7-step digital occlusion set-up process for patients with class III malocclusion. The average root mean square difference of the final occlusion between the conventional occlusion set-up group, in which dental casts were used, and the virtual occlusion set-up group was below $0.5 \mathrm{~mm}$, indicating that the results were accurate and reliable. Furthermore, the virtual occlusion set-up required only 40 minutes, whereas the conventional occlusion set-up required approximately 140 minutes $[14,37]$. Seo et al. $[15,38]$ reported a standardized protocol of virtual occlusion set-up with the fabrication of a surgical splint for unilateral cleft patients, with results that were comparable to those of the conventional occlusion set-up method (Fig. 4). It is important that the plastic surgeon and orthodontist collaborate in all surgical planning, including the surgical occlusion set-up, to enhance the completeness of overall surgical planning and increase the feasibility of surgery.

\section{SURGICAL PROCEDURE}

\section{Single-splint technique versus double-splint technique}

Orthognathic surgery could be performed with either the single-splint or the double-splint technique. The single-splint technique is characterized by the use of only a single final splint

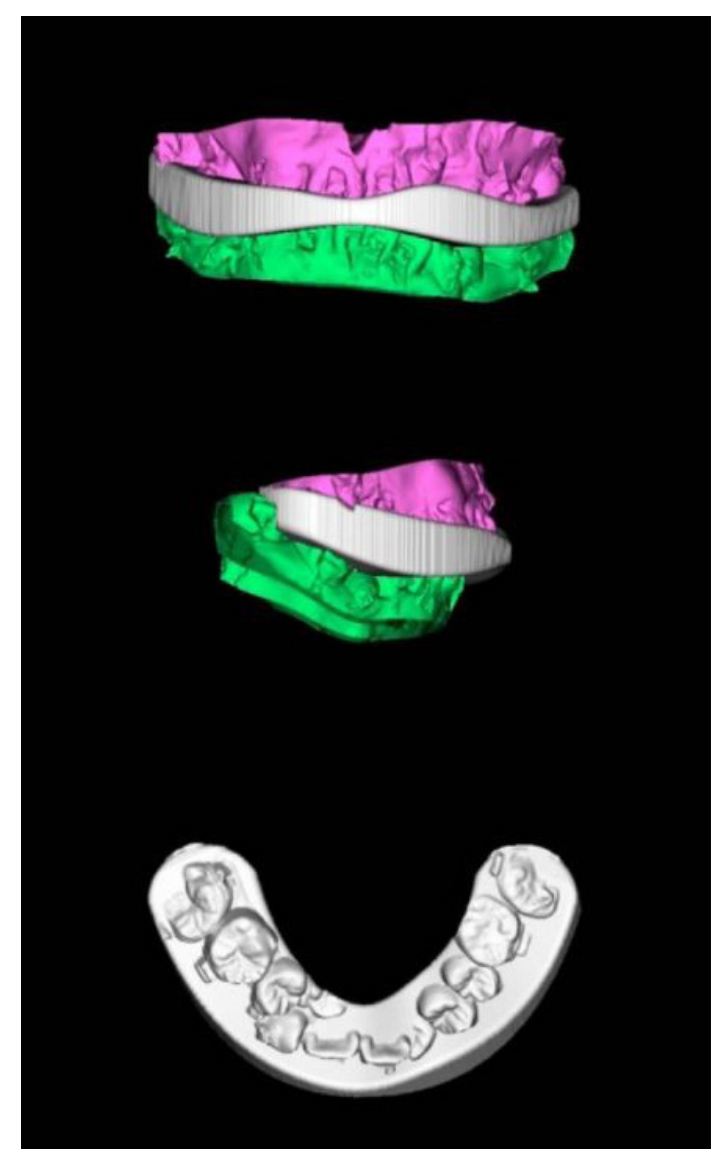

Fig. 4. Computer-generated three-dimensional surgical occlusion splint using surgery-first approach. Reprinted from Seo et al. J Clin Med 2019;8:2116 [15].

with free-hand positioning of the maxillomandibular complex. The double-splint technique, in contrast, is characterized by the use of an intermediate splint first to position the maxilla/mandibular segment, followed by application of the final splint to position the other segment [39-41]. However, it is unclear which technique yields superior surgical outcomes.

In the single-splint technique, after LeFort I osteotomy and BSSO, the maxillary and mandibular segments are placed into temporary intermaxillary fixation with a final occlusal splint. The maxillomandibular complex is repositioned according to data based on the preoperative 3D analysis and fixed to the stable upper maxillary base. The position of the maxillomandibular complex could be adjusted to a small degree based on the following check-points: (1) midline coordination, (2) upper incisor show, (3) the intercommissural line, (4) facial contour symmetry in the frontal view, (5) cheek symmetry in the frontal view, (6) paranasal fullness, (7) the Ricketts E-line, and (8) lower face proportions [41]. Mild under- or over-correction of bony movement is possible using the single-splint technique, which is advantageous for achieving soft tissue symmetry 
$[40,42]$. In previous cases with 2D surgical planning, this advantage was very attractive. However, a steep learning curve is required and the results strongly depend on the surgeon's experience; furthermore, significant error was observed in the pitch rotation of the maxillomandibular complex compared to $3 \mathrm{D}$ planning $[43,44]$.

The double-splint technique is a classic method that has been widely used since the period when $2 \mathrm{D}$ cephalometry was used with model surgery. A major advantage of the double-splint technique is a relatively short operation time with less dependence on the surgeon's ability. With recent advances in $3 \mathrm{D}$ virtual analysis and manufacturing systems, the double-splint technique has made it possible to translate the precise $3 \mathrm{D}$ planned skeletal movement to surgery using a 3D-printed intermediate splint $[27,45]$. A comparative study between the single-splint group and double-splint techniques was performed in 2018, and there were no significant differences in overall soft tissue symmetry in the frontal view and the Orthognathic Quality of Life questionnaire [39].

\section{Mandible-first versus maxilla-first approach}

The decision regarding the operation sequence of two-jaw orthognathic surgery using the double-splint technique (i.e., either maxilla-first or mandible-first surgery) remains controversial and depends on the surgeon's comfort level with the surgical technique and sequence.

Classically, maxilla-first surgery begins from mandibular bilateral sagittal split corticotomies, followed by complete LeFort I osteotomy with repositioning of the maxillary segment using an intermediate splint, and finally complete BSSO and repositioning of the distal segment of the mandible using a final splint. Complete BSSO does not require a wide mouth opening, which could cause an alteration of the fixed maxillary position. Salmen et al. [46] and Liebregts et al. [47] reported that in the context of planned maxillary impaction and with most surgical movements, the maxilla-first sequence was more accurate.

Mandible-first surgery starts with complete BSSO initially, followed by repositioning and fixation of the distal segment of the mandible using an intermediate splint. Next, LeFort I osteotomy and repositioning of the maxilla are performed using the final splint. There are several indications that are suitable for mandible-first, surgery including cases with (1) counterclockwise rotation of the occlusal plane, (2) segmental maxillary osteotomies, (3) cleft maxilla, (4) downgrafting of the posterior maxilla, (5) large maxillomandibular advancement (MMA), (6) anterior open bite, and (7) inability to accurately register the bite [48].

A comparative study of the accuracy of maxilla-first versus mandible-first surgery was performed in 2021. Despite both sequences being performed under similar conditions (operation and follow-up by the same team of surgeons and orthodontists) it was concluded that the mandible-first surgery group presented more accuracy in the vertical dimension and that splint thickness had no effect on surgical accuracy with proper selection of the intermediate splint [49].

\section{OTHER ISSUES IN THE FIELD OF ORTHOGNATHIC SURGERY}

\section{Treatment of OSA}

In the treatment of OSA, orthognathic surgery with MMA is emerging as the most effective surgical procedure [50,51]. In particular, advancement of the mandibular segment pulls the tongue base in the forward direction, which is helpful for widening of the velopharyngeal airway. Advancement of the maxilla tightens the soft palate and contributes to opening the velopharynx [52,53].

Nasal continuous positive airway pressure (nCPAP) is generally considered as the first-line treatment for OSA due to its high therapeutic efficacy and convenience of pneumatically splitting open the airway; however, its low compliance rate due to patient intolerance is a drawback of nCPAP treatment [5456]. The therapeutic efficacy of MMA has been shown to be almost equal to that of nCPAP; therefore, MMA is becoming popular due to its high success rate [57]. Prinsell [58] reported that the mean percent reduction in the apnea-hypopnea index (AHI) was $92.1 \%$ for primary MMA with an extrapharyngeal procedure, $88.4 \%$ for primary MMA, $53.0 \%$ for non-MMA multilevel surgery, and $31.3 \%$ for uvulopalatopharyngoplasty (Table 1).

The advancement of the maxillomandibular complex via a counterclockwise rotation wound achieves both airway enlargement and an aesthetically pleasing straight facial profile with limited advancement of the A-point. Advancing the mandible

Table 1. Percent reduction in AHI for different treatment methods

\begin{tabular}{lc}
\hline Treatment methods & Mean reduction in AHI (\%) \\
\hline nCPAP & 89.8 \\
Primary MMA with extrapharyngeal procedures & 92.1 \\
Primary MMA & 88.4 \\
Secondary MMA & 86.6 \\
Primary MMA with intrapharyngeal procedures & 79.4 \\
Non-MMA multilevel surgery & 53.0 \\
Uvulopalatopharyngoplasty & 31.3
\end{tabular}

AHI, apnea-hypopnea index; nCPAP, nasal continuous positive airway pressure; MMA, maxillomandibular advancement. 
by at least $10 \mathrm{~mm}$ is highly recommended to maximize airway enlargement [51]. The relapse rate of MMA has been reported to vary from $10 \%$ to $20 \%$; however, the $\mathrm{AHI}$ remains consistent despite skeletal and soft tissue relapse. MMA is considered to provide the most consistent and effective reduction in the AHI for OSA patients [2,59].

\section{Adjunct procedures for facial asymmetry correction}

The face is made up of both bones and soft tissue, and it is difficult to perfectly correct the overall balance by changing the skeletal frame through orthognathic surgery if the soft tissue is asymmetric. Furthermore, changes in the soft tissue do not exactly match changes in the skeletal frame. Botulinum toxin injection is used to correct facial asymmetry [60]. But, it has only a temporary effect. An autologous fat graft is a useful procedure for correcting soft tissue deficiencies with long-lasting results [61]. For patients with facial asymmetry, the difference in the jawline and lateral cheek area often remains even after orthognathic surgery. Wang et al. [62] reported that orthognathic surgery with a simultaneous autologous fat graft could be a good option for further improving facial asymmetry and achieving more aesthetically pleasing results. Adipose-derived stem cells within the fat graft have the additional effects of improving skin texture, reducing postoperative edema, and softening the preexisting scar $[63,64]$. Genioplasty and malar reduction surgery could also be helpful for additional correction of bony symmetry [65].

\section{Future digital technology with orthognathic surgery}

With rapid technological developments, image-navigation technology, augmented reality (AR), artificial intelligence (AI), and robotic-assisted orthognathic surgery have been applied in the field of orthognathic surgery. Robot-assisted orthognathic surgery is a combination of robotic technology and a navigation system. Wu et al. [66] reported that robot-performed complete osteotomy following preoperative virtual surgical planning, with the plan transferred into actual surgery, showed good accuracy and feasibility. AR, which enables virtualization of the patient data directly at the operative site, could provide more accurate knowledge of the patient's internal anatomy and pathology [67]. AI can be applied to imagery, planning, customized orthodontics, appliances, and follow-up [68]. In future studies, technology-assisted orthognathic surgical methods will be applied to actual patients, and further research and analyses will continue.

\section{CONCLUSION}

Orthognathic surgery plays an important role in the craniofa- cial field to correct both functional and aesthetic problems. The recent trend has been to minimize the period of preoperative orthodontic treatment to reduce patients' discomfort and to improve compliance. In addition, the significance of orthognathic surgery using MMA for the treatment of OSA has increased in recent years. However, orthognathic surgery cannot guarantee perfect results in terms of soft tissue balance, and an adjunct procedure including a simultaneous fat graft could be helpful for correcting soft tissue deficiencies. In the future, it is predicted that various types of orthognathic surgery that incorporate AR, AI, or robot technology will be developed and implemented, beyond the current 3D virtual technology used for surgical planning and splint fabrication.

\section{NOTES}

\section{Conflict of interest}

No potential conflict of interest relevant to this article was reported.

\section{Patient consent}

The patients provided written informed consent for the publication and the use of their images.

\section{ORCID}

Hyung Joon Seo Thtp://orcid.org/0000-0003-1111-492X

Youn-Kyung Choi https://orcid.org/0000-0003-1491-2986

\section{Author contribution}

Conceptualization: Hyung Joon Seo, Youn-Kyung Choi. Data curation: Hyung Joon Seo, Youn-Kyung Choi. Writing - original draft: Hyung Joon Seo. Writing - review \& editing: YounKyung Choi. Supervision: Hyung Joon Seo, Youn-Kyung Choi.

\section{REFERENCES}

1. Wu RT, Wilson AT, Gary CS, Steinbacher DM. Complete reoperation in orthognathic surgery. Plast Reconstr Surg 2019;143: 1053e-1059e.

2. Naran S, Steinbacher DM, Taylor JA. Current concepts in orthognathic surgery. Plast Reconstr Surg 2018;141:925e-936e.

3. Rosen HM. Evolution of a surgical philosophy in orthognathic surgery. Plast Reconstr Surg 2017;139:978-90.

4. Steinhauser EW. Historical development of orthognathic surgery. J Craniomaxillofac Surg 1996;24:195-204.

5. Bell RB. A history of orthognathic surgery in North America. J Oral Maxillofac Surg 2018;76:2466-81.

6. Aziz SR. Simon P. Hullihen and the origin of orthognathic sur- 
gery. J Oral Maxillofac Surg 2004;62:1303-7.

7. Rosen HM. Facial skeletal expansion: treatment strategies and rationale. Plast Reconstr Surg 1992;89:798-808.

8. Selber JC, Rosen HM. Aesthetics of facial skeletal surgery. Clin Plast Surg 2007;34:437-45.

9. Liou EJ, Chen PH, Wang YC, Yu CC, Huang CS, Chen YR. Surgery-first accelerated orthognathic surgery: orthodontic guidelines and setup for model surgery. J Oral Maxillofac Surg 2011;69:771-80.

10. Luther F, Morris DO, Hart C. Orthodontic preparation for orthognathic surgery: how long does it take and why? A retrospective study. Br J Oral Maxillofac Surg 2003;41:401-6.

11. Jacobs JD, Sinclair PM. Principles of orthodontic mechanics in orthognathic surgery cases. Am J Orthod 1983;84:399-407.

12. Choi JW, Bradley JP. Surgery first orthognathic approach without presurgical orthodontic treatment: questions and answers. J Craniofac Surg 2017;28:1330-3.

13. Choi JW, Lee JY. Current concept of the surgery-first orthognathic approach. Arch Plast Surg 2021;48:199-207.

14. Ho CT, Lin HH, Lo LJ. Intraoral scanning and setting up the digital final occlusion in three-dimensional planning of orthognathic surgery: its comparison with the dental model approach. Plast Reconstr Surg 2019;143:1027e-1036e.

15. Seo HJ, Denadai R, Pai BC, Lo LJ. Modern surgery-first approach concept in cleft-orthognathic surgery: a comparative cohort study with 3D quantitative analysis of surgical-occlusion setup. J Clin Med 2019;8:2116.

16. Oh CO, Son HB. Functional orthognathic surgery (1). Korean J Clin Orthod 2002;1:32-9.

17. Liou EJ, Chen PH, Wang YC, Yu CC, Huang CS, Chen YR. Surgery-first accelerated orthognathic surgery: postoperative rapid orthodontic tooth movement. J Oral Maxillofac Surg 2011;69:781-5.

18. Choi JW, Jeong WS, Kang MK, Lee JY, Chung YS. Counterclockwise rotational orthognathic surgery for the obstructive sleep apnea in class II dentofacial deformity: polysomnography and 3D computed tomographic analysis. Ann Plast Surg 2021; 86:640-6.

19. Jeong WS, Choi JW, Kim DY, Lee JY, Kwon SM. Can a surgeryfirst orthognathic approach reduce the total treatment time? Int J Oral Maxillofac Surg 2017;46:473-82.

20. Hernandez-Alfaro F, Guijarro-Martinez R, Peiro-Guijarro MA. Surgery first in orthognathic surgery: what have we learned? A comprehensive workflow based on 45 consecutive cases. J Oral Maxillofac Surg 2014;72:376-90.

21. Liao YF, Chiu YT, Huang CS, Ko EW, Chen YR. Presurgical orthodontics versus no presurgical orthodontics: treatment outcome of surgical-orthodontic correction for skeletal class
III open bite. Plast Reconstr Surg 2010;126:2074-83.

22. Yang L, Xiao YD, Liang YJ, Wang X, Li JY, Liao GQ. Does the surgery-first approach produce better outcomes in orthognathic surgery? A systematic review and meta-analysis. J Oral Maxillofac Surg 2017;75:2422-9.

23. Choi JW, Lee JY, Yang SJ, Koh KS. The reliability of a surgeryfirst orthognathic approach without presurgical orthodontic treatment for skeletal class III dentofacial deformity. Ann Plast Surg 2015;74:333-41.

24. Lee TS, Park S. Clockwise rotation of the occlusal plane for aesthetic purposes by double jaw surgery without orthodontic treatment. Plast Reconstr Surg 2019;144:1010e-1013e.

25. Wolford LM, Chemello PD, Hilliard FW. Occlusal plane alteration in orthognathic surgery. J Oral Maxillofac Surg 1993;51:73041.

26. Choi JW, Jeong WS. Occlusal plane altering 2 jaw surgery based on the clockwised rotational surgery-first orthognathic approach. Plast Reconstr Surg Glob Open 2017;5:e1492.

27. Wu TY, Lin HH, Lo LJ, Ho CT. Postoperative outcomes of twoand three-dimensional planning in orthognathic surgery: a comparative study. J Plast Reconstr Aesthet Surg 2017;70:110111.

28. Wilson A, Gabrick K, Wu R, Madari S, Sawh-Martinez R, Steinbacher D. Conformity of the actual to the planned result in orthognathic surgery. Plast Reconstr Surg 2019;144:89e-97e.

29. Lin HH, Lo LJ. Three-dimensional computer-assisted surgical simulation and intraoperative navigation in orthognathic surgery: a literature review. J Formos Med Assoc 2015;114:300-7.

30. Hammoudeh JA, Howell LK, Boutros S, Scott MA, Urata MM. Current status of surgical planning for orthognathic surgery: traditional methods versus 3D surgical planning. Plast Reconstr Surg Glob Open 2015;3:e307.

31. Alkhayer A, Piffko J, Lippold C, Segatto E. Accuracy of virtual planning in orthognathic surgery: a systematic review. Head Face Med 2020;16:34.

32. Resnick CM, Inverso G, Wrzosek M, Padwa BL, Kaban LB, Peacock ZS. Is there a difference in cost between standard and virtual surgical planning for orthognathic surgery? J Oral Maxillofac Surg 2016;74:1827-33.

33. Hsu PJ, Denadai R, Pai BC, Lin HH, Lo LJ. Outcome of facial contour asymmetry after conventional two-dimensional versus computer-assisted three-dimensional planning in cleft orthognathic surgery. Sci Rep 2020;10:2346.

34. Mazzoni S, Bianchi A, Schiariti G, Badiali G, Marchetti C. Computer-aided design and computer-aided manufacturing cutting guides and customized titanium plates are useful in upper maxilla waferless repositioning. J Oral Maxillofac Surg 2015;73:701-7. 
35. O’Malley AM, Milosevic A. Comparison of three facebow/ semi-adjustable articulator systems for planning orthognathic surgery. Br J Oral Maxillofac Surg 2000;38:185-90.

36. Sharifi A, Jones R, Ayoub A, Moos K, Walker F, Khambay B, et al. How accurate is model planning for orthognathic surgery? Int J Oral Maxillofac Surg 2008;37:1089-93.

37. Grunheid T, McCarthy SD, Larson BE. Clinical use of a direct chairside oral scanner: an assessment of accuracy, time, and patient acceptance. Am J Orthod Dentofacial Orthop 2014;146: 673-82.

38. Seo HJ, Denadai R, Pai BC, Lo LJ. Digital occlusion setup is quantitatively comparable with the conventional dental model approach: characteristics and guidelines for orthognathic surgery in patients with unilateral cleft lip and palate. Ann Plast Surg 2020;85:171-9.

39. Ng JH, Chen YA, Hsieh YJ, Yao CF, Liao YF, Chen YR. Onesplint versus two-splint technique in orthognathic surgery for class III asymmetry: comparison of patient-centred outcomes. Clin Oral Investig 2021;25:6799-811.

40. Bergeron L, Yu CC, Chen YR. Single-splint technique for correction of severe facial asymmetry: correlation between intraoperative maxillomandibular complex roll and restoration of mouth symmetry. Plast Reconstr Surg 2008;122:1535-41.

41. Yu CC, Bergeron L, Lin CH, Chu YM, Chen YR. Single-splint technique in orthognathic surgery: intraoperative checkpoints to control facial symmetry. Plast Reconstr Surg 2009;124:87986.

42. Ko EW, Huang CS, Chen YR. Characteristics and corrective outcome of face asymmetry by orthognathic surgery. J Oral Maxillofac Surg 2009;67:2201-9.

43. Hatef DA, Hollier LH Jr. Discussion. Single-splint technique in orthognathic surgery: intraoperative checkpoints to control facial symmetry. Plast Reconstr Surg 2009;124:887.

44. Ko EW, Lin CH, Chen YA, Chen YR. Enhanced surgical outcomes in patients with skeletal class III facial asymmetry by 3-dimensional surgical simulation. J Oral Maxillofac Surg 2018;76:1073-83.

45. De Riu G, Meloni SM, Baj A, Corda A, Soma D, Tullio A. Computer-assisted orthognathic surgery for correction of facial asymmetry: results of a randomized controlled clinical trial. Br J Oral Maxillofac Surg 2014;52:251-7.

46. Salmen FS, de Oliveira TF, Gabrielli MA, Pereira Filho VA, Real Gabrielli MF. Sequencing of bimaxillary surgery in the correction of vertical maxillary excess: retrospective study. Int J Oral Maxillofac Surg 2018;47:708-14.

47. Liebregts J, Baan F, de Koning M, Ongkosuwito E, Berge S, Maal T, et al. Achievability of 3D planned bimaxillary osteotomies: maxilla-first versus mandible-first surgery. Sci Rep 2017;
7:9314.

48. Borba AM, Borges AH, Ce PS, Venturi BA, Naclerio-Homem MG, Miloro M. Mandible-first sequence in bimaxillary orthognathic surgery: a systematic review. Int J Oral Maxillofac Surg 2016;45:472-5.

49. Borikanphanitphaisan T, Lin CH, Chen YA, Ko EW. Accuracy of mandible-first versus maxilla-first approach and of thick versus thin splints for skeletal position after two-jaw orthognathic surgery. Plast Reconstr Surg 2021;147:421-31.

50. Guilleminault C, Quera-Salva MA, Powell NB, Riley RW. Maxillo-mandibular surgery for obstructive sleep apnoea. Eur Respir J 1989;2:604-12.

51. Lin CH, Liao YF, Chen NH, Lo LJ, Chen YR. Three-dimensional computed tomography in obstructive sleep apneics treated by maxillomandibular advancement. Laryngoscope 2011;121:133647.

52. Gindre L, Gagnadoux F, Meslier N, Gustin JM, Racineux JL. Mandibular advancement for obstructive sleep apnea: dose effect on apnea, long-term use and tolerance. Respiration 2008;76: 386-92.

53. Liu SY, Huon LK, Ruoff C, Riley RW, Strohl KP, Peng Z. Restoration of sleep architecture after maxillomandibular advancement: success beyond the apnea-hypopnea index. Int J Oral Maxillofac Surg 2017;46:1533-8.

54. Gay P, Weaver T, Loube D, Iber C; Positive Airway Pressure Task Force; Standards of Practice Committee, et al. Evaluation of positive airway pressure treatment for sleep related breathing disorders in adults. Sleep 2006;29:381-401.

55. McArdle N, Devereux G, Heidarnejad H, Engleman HM, Mackay TW, Douglas NJ. Long-term use of CPAP therapy for sleep apnea/hypopnea syndrome. Am J Respir Crit Care Med 1999;159(4 Pt 1):1108-14.

56. Sin DD, Mayers I, Man GC, Pawluk L. Long-term compliance rates to continuous positive airway pressure in obstructive sleep apnea: a population-based study. Chest 2002;121:430-5.

57. Li KK, Powell NB, Riley RW, Troell RJ, Guilleminault C. Longterm results of maxillomandibular advancement surgery. Sleep Breath 2000;4:137-40.

58. Prinsell JR. Primary and secondary telegnathic maxillomandibular advancement, with or without adjunctive procedures, for obstructive sleep apnea in adults: a literature review and treatment recommendations. J Oral Maxillofac Surg 2012;70: 1659-77.

59. Gokce SM, Gorgulu S, Gokce HS, Bengi O, Sabuncuoglu F, Ozgen F, et al. Changes in posterior airway space, pulmonary function and sleep quality, following bimaxillary orthognathic surgery. Int J Oral Maxillofac Surg 2012;41:820-9.

60. Park MY, Ahn KY. Scientific review of the aesthetic uses of 
botulinum toxin type A. Arch Craniofac Surg 2021;22:1-10.

61. Swanson E. Malar augmentation assessed by magnetic resonance imaging in patients after face lift and fat injection. Plast Reconstr Surg 2011;127:2057-65.

62. Wang YC, Wallace CG, Pai BC, Chen HL, Lee YT, Hsiao YC, et al. Orthognathic surgery with simultaneous autologous fat transfer for correction of facial asymmetry. Plast Reconstr Surg 2017;139:693-700.

63. Lisa A, Maione L, Vinci V, Rimondo A, Klinger F, Klinger M. The use of autologous fat grafting for treatment of scar tissue and scar-related conditions: a systematic review. Plast Reconstr Surg 2016;138:1076e-1077e.

64. Cabrejo R, DeSesa CR, Sawh-Martinez R, Steinbacher DM. Does fat grafting influence postoperative edema in orthogna- thic surgery? J Craniofac Surg 2017;28:1906-10.

65. Yamaguchi K, Lonic D, Ko EW, Lo LJ. An integrated surgical protocol for adult patients with hemifacial microsomia: methods and outcome. PLoS One 2017;12:e0177223.

66. Wu J, Hui W, Chen S, Niu J, Lin Y, Luan N, et al. Error analysis of robot-assisted orthognathic surgery. J Craniofac Surg 2020; 31:2324-8.

67. Kim SH, Lee SJ, Choi MH, Yang HJ, Kim JE, Huh KH, et al. Quantitative augmented reality-assisted free-hand orthognathic surgery using electromagnetic tracking and skin-attached dynamic reference. J Craniofac Surg 2020;31:2175-81.

68. Ryu JY, Chung HY, Choi KY. Potential role of artificial intelligence in craniofacial surgery. Arch Craniofac Surg 2021;22:22331. 